\title{
COVID-19 Vaccine Interest among Corrections Officers and People Who Are Incarcerated at Middlesex County Jail, Massachusetts
}

\author{
Sarah B. Khorasani $[$ • Peter J. Koutoujian • Julia \\ Zubiago • Rubeen Guardado • Kashif Siddiqi • Alysse \\ G. Wurcel
}

Accepted: 19 April 2021/ Published online: 26 May 2021

(C) The New York Academy of Medicine 2021

\section{Introduction}

Jails are epicenters of COVID-19 transmission, and both people who work in jails and people incarcerated there are at increased risk of COVID-19 [1-3]. Massachusetts prioritized individuals working and living in carceral settings for COVID-19 vaccination in phase 1 of the vaccine rollout [4]. National data have reflected trends of COVID-19 vaccine hesitancy, particularly among communities of color-a population disproportionately represented in criminal legal-involved populations [5, 6]. Even with efforts to secure and distribute vaccines as quickly as possible, there remains a paucity of data reflecting attitudes toward COVID-19 vaccination among people who are incarcerated or people who are working in jails. In preparation for institution-wide vaccination, the Middlesex Sheriff's Office (MSO) developed and distributed two self-response surveys in December 2020 and January 2021 to assess COVID-19 vaccine willingness among people incarcerated in the jail and one for people who work at the jail. The goal of

\footnotetext{
S. B. Khorasani · A. G. Wurcel $(\bowtie)$

Tufts University School of Medicine, 145 Harrison Ave, Boston, MA 02111, USA

e-mail: awurcel@tuftsmedicalcenter.org
}

P. J. Koutoujian · K. Siddiqi · A. G. Wurcel

Middlesex Sheriff's Office, Medford, MA, USA

J. Zubiago · R. Guardado

Tufts Medical Center, Boston, MA, USA this study is to characterize vaccine willingness in these two populations of people at the Middlesex House of Correction and Jail with the ultimate goal of informing communication strategies to address concerns and increase acceptance of COVID-19 vaccination.

\section{Methods}

An exemption was received from the Tufts Health Sciences Institutional Review Board to analyze deidentified data following the MSO internal analysis.

\section{Cohort}

People incarcerated in the jail in December 2020 and January 2021 were asked to respond to the survey on tablets prior to accessing educational and entertainment with an option to bypass the survey. Paper surveys were distributed where tablets were unavailable. All staff were emailed a link to an online survey and were encouraged to participate at daily roll call and through follow-up reminder emails.

\section{Survey Questions}

People were asked if they would be willing to accept the COVID-19 vaccine, and if they said no, they were asked to select their primary reason for refusal. Incarcerated individuals who indicated unwillingness to receive the COVID-19 vaccine were also asked if they would be 
willing to reconsider their refusal. All participants were asked to report their race, age (incarcerated individuals gave the number, and employees selected a range), and gender (male/female/choose not to disclose). Incarcerated individuals were asked whether they were pre-trial or sentenced and employees were asked to select their professional roles.

\section{Statistical Analysis}

Only respondents who answered demographic questions in addition to the question about vaccine willingness were included in the analysis. Descriptive statistics were calculated for each survey population, and univariable and multivariable logistic regressions were done to assess the relationship between demographic factors and willingness to accept a COVID-19 vaccine. All analyses were done using RStudio Version 1.3.1093.

\section{Results}

Overall, 505 incarcerated individuals responded to the survey for a response rate of $82 \%$; 443 people were included for analysis. A total of 254 staff members completed the survey for a response rate of $37 \%$, and 245 staff were included for analysis. Summary characteristics and the results of the univariable and multivariable logistic regressions are shown in Table 1. Fifty-nine percent of people incarcerated in jail did not want the COVID-19 vaccine, and of this group, $33 \%$ were open to changing their minds. Incarcerated individuals who did not want the vaccine cited general mistrust in vaccines (31\%), concerns about vaccine safety (22\%) and effectiveness $(8 \%)$, needing further information (15\%), concerns about the rushed timeline (8\%), or had another reason (15\%). Among people who were incarcerated, those who identified as Black had significantly decreased odds of wanting the COVID19 vaccine than those who identified as white (adjusted OR $0.55, p<0.05)$.

Eighty-two percent of jail staff were interested in receiving the COVID-19 vaccine. Staff who did not want the vaccine cited concerns about vaccine safety $(43 \%)$ and efficacy $(5 \%)$, general mistrust in vaccines (20\%), concerns about the rushed timeline (18\%), or another reason $(11 \%)$. Race was not significantly associated with vaccine willingness among jail employees when adjusting for role and gender. Uniformed correctional officers were less likely than medical or mental health staff to indicate vaccine willingness (adjusted OR $0.09, p<0.05$ ), though $76 \%$ of uniformed correctional officers indicated willingness to accept the COVID-19 vaccine.

\section{Discussion}

The COVID-19 vaccine is an important tool, but only if people accept it. Our data show the majority of people incarcerated in jail were not interested in receiving the COVID-19 vaccine and that incarcerated individuals who identified as Black were significantly less likely to want a COVID-19 vaccine. Addressing misinformation and mistrust are the critical next steps for overcoming hesitancy and vaccinating people who are incarcerated and people who work in jails.

Recent studies have noted that non-incarcerated Black Americans are especially likely to be hesitant to receive the COVID-19 vaccine compared to members of other racial groups $[5,7]$. A recent multi-site study of people incarcerated or detained in prisons and jails found that fewer than half of participants would be willing to accept a COVID-19 vaccine and that willingness was lowest among Black participants and those incarcerated in jails [8]. Concerns about vaccination are frequently related to the speed of the COVID-19 vaccine development and distribution and exist within the paradigm of historical abuses of Black people by medical and correctional professionals [9-11]. Given that both communities of color and people who are incarcerated have faced a disproportionate burden of COVID-19-associated morbidity and mortality, correctional facilities must identify the particular vaccinerelated concerns among people of color who are incarcerated [12-14].

In this facility, though some individuals were unwilling to reconsider vaccination, $33 \%$ of incarcerated people who reported not wanting a vaccine were willing to learn more. Concerns around the accelerated timeline and about COVID-19 vaccine safety were reported in both groups. Among both incarcerated individuals and staff, general mistrust of vaccines informed COVID-19specific vaccine hesitancy. Similar concerns about COVID-19 vaccination have been reported in other populations such as medical students, nurses, and nonincarcerated adults $[6,15,16]$. Targeted education by stakeholders and peer-to-peer discussions have increased vaccine willingness in other populations, and 
Table 1 Association of demographic, incarceration-related, and job-related variables with willingness to receive a COVID-19 vaccine among people incarcerated and staff in a Massachusetts jail

\begin{tabular}{|c|c|c|c|c|c|}
\hline \multirow[t]{2}{*}{ Variable } & \multirow[t]{2}{*}{ Entire cohort } & \multicolumn{2}{|c|}{$\begin{array}{l}\text { Willing to accept COVID-19 vac- } \\
\text { cine* }^{*}\end{array}$} & \multirow[t]{2}{*}{ Univariable OR (95\% CI) } & \multirow[t]{2}{*}{ Multivariable OR $(95 \% \mathrm{CI})$} \\
\hline & & Yes & No & & \\
\hline People incarcerated in jail & $n=443$ & $181(41 \%)$ & $262(59 \%)$ & -- & -- \\
\hline Age $($ mean $\pm \mathrm{SD})$ & $36 \pm 11$ & $39 \pm 12$ & $34 \pm 11$ & $1.04(1.02,1.06)$ & $1.04(1.02,1.06)$ \\
\hline \multicolumn{6}{|l|}{$\operatorname{Race}(n,(\%))$} \\
\hline White & $162(37)$ & $75(41)$ & $87(33)$ & Reference & Reference \\
\hline Asian & $15(3.4)$ & $6(3.3)$ & $9(3.4)$ & $0.76(0.25,2.22)$ & $0.72(0.23,2.15)$ \\
\hline Black & $109(25)$ & $33(4.1)$ & $76(29)$ & $0.50(0.29,0.83)$ & $0.55(0.32,0.93)$ \\
\hline Hispanic & $157(35)$ & $67(37)$ & $90(34)$ & $0.84(0.54,1.31)$ & $1.03(0.64,1.63)$ \\
\hline Other & $5(1.1)$ & $2(1.1)$ & $3(1.1)$ & $0.76(0.10,4.73)$ & $0.89(0.11,5.99)$ \\
\hline \multicolumn{6}{|c|}{ Incarceration status $(n,(\%))$} \\
\hline Pre-trial & $304(68.6)$ & $126(41.4)$ & $178(59)$ & Reference & Reference \\
\hline Sentenced & $139(31.4)$ & $55(39.6)$ & $84(60)$ & $0.92(0.61,1.39)$ & $0.82(0.53,1.25)$ \\
\hline Correctional Staff $(n, \%)$ & $n=245$ & $201(82 \%)$ & $44(18 \%)$ & -- & -- \\
\hline \multicolumn{6}{|l|}{ Age $(n,(\%))$} \\
\hline $56+$ & 47 (19) & $41(20)$ & $6(14)$ & Reference & Reference \\
\hline $45-55$ & $78(32)$ & $69(34)$ & $9(21)$ & $1.12(0.35,3.34)$ & $1.48(0.44,4.73)$ \\
\hline $35-45$ & $69(28)$ & $52(26)$ & $17(39)$ & $0.45(0.15,1.18)$ & $0.59(0.19,1.71)$ \\
\hline $25-34$ & $49(20)$ & $38(19)$ & $11(25)$ & $0.51(0.16,1.46)$ & $0.71(0.21,2.25)$ \\
\hline $18-24$ & $2(0.80)$ & $1(0.5)$ & $1(2.2)$ & $0.15(0.01,4.02)$ & $0.12(0.00,3.69)$ \\
\hline Male $(n,(\%))$ & $177(72.2)$ & $149(74.1)$ & $28(64)$ & $1.64(0.81,3.24)$ & $3.28(1.30,8.57)$ \\
\hline \multicolumn{6}{|l|}{$\operatorname{Race}(n,(\%))$} \\
\hline White & $217(88.6)$ & $182(91)$ & $35(80)$ & Reference & Reference \\
\hline Asian & $7(2.9)$ & $5(2.5)$ & $2(4.5)$ & $0.48(0.10,7.59)$ & $0.80(0.15,6.15)$ \\
\hline Black & $12(4.9)$ & $7(3.5)$ & $5(11.4)$ & $0.27(0.08,0.95)$ & $0.42(0.10,1.77)$ \\
\hline Hispanic & $5(2.0)$ & $4(2.0)$ & $1(2.3)$ & $0.77(0.11,15.29)$ & $0.67(0.09,13.59)$ \\
\hline Another Race & $4(1.6)$ & $3(1.5)$ & $1(2.3)$ & $0.58(0.07,11.85)$ & $0.49(0.05,10.81)$ \\
\hline \multicolumn{6}{|l|}{ Role $(n,(\%))$} \\
\hline Medical/mental health & $24(9.8)$ & $22(10.9)$ & $2(4.5)$ & Reference & Reference \\
\hline Administrative & $52(21.2)$ & $44(21.9)$ & $8(18)$ & $0.50(0.07,2.21)$ & $0.21(0.03,1.12)$ \\
\hline Operational or facilities & $25(10.2)$ & $22(10.9)$ & $3(6.8)$ & $0.67(0.08,4.40)$ & $0.21(0.02,1.66)$ \\
\hline Program services & $31(12.7)$ & $27(13.4)$ & $4(9.1)$ & $0.61(0.08,3.45)$ & $0.34(0.04,2.12)$ \\
\hline Uniformed correctional & $109(44.5)$ & $83(41.3)$ & $26(59)$ & $0.29(0.04,1.08)$ & $0.09(0.01,0.46)$ \\
\hline Vendor/contractor/other & $4(1.6)$ & $3(1.5)$ & $1(2.3)$ & $0.27(0.02,6.90)$ & $0.21(0.01,5.96)$ \\
\hline
\end{tabular}

*Question asked: "If an FDA-approved vaccine to prevent coronavirus / COVID-19 was available to you right now at no cost, would you agree to be vaccinated?"

Bolded values represent statistically significant findings with $p<0.05$

likely would help address vaccine-related concerns among people incarcerated or working in jails [17, 18]. Our anecdotal experience in Massachusetts facilities suggests that "Ask Me Anything About the COVID19 Vaccine" sessions with incarcerated individuals and corrections officers facilitated by medical students and health care providers from the community has resulted in increased interest in COVID-19 vaccine uptake.

Over three quarters of the uniformed correctional officers who responded to the survey indicated 
willingness to accept the COVID-19 vaccine, higher than the previously reported interest among corrections officers of closer to $50 \%$ [19]. The high reported interest in the COVID-19 vaccine among the correctional staff at Middlesex County may reflect differences in jail and prison employees and the strong relationship between Massachusetts' public health infrastructure and the infection control response in the jails. However, the high reported interest among correctional staff appears to overstate desired vaccine uptake with preliminary data from Middlesex County reflecting an actual COVID-19 vaccination rate of just over 55\% (278/498) among uniformed correctional staff [email communication with MSO April 5, 2021].

Several limitations should be considered. This survey was not piloted prior to dissemination nor was it designed for research purposes. The low staff response rate suggests possible response bias, which, given preliminary vaccination data from the jail, likely overestimates true vaccine willingness in this population. It is likely that individuals interested in vaccination would be more engaged in answering a survey to this effect. Furthermore, most of the employees in the jail were white, weakening the ability to understand the impact of race of staff members on interest in the COVID-19 vaccine. The racial distribution of individuals incarcerated within this particular jail may not match other carceral settings in the country. None of the incarcerated individuals surveyed identified as female, and their responses are not representative of individuals who identify as female. Additionally, low sample sizes could have affected statistical analyses towards the null.

Our analysis underscores the need to address gaps in knowledge in order to meet the particular health needs of those experiencing incarceration. Without a concerted effort to engage individuals living in carceral settings in vaccination efforts, we risk perpetuating already severe health inequities in our most vulnerable and marginalized communities.

\section{Acknowledgments 1KL2TR002545-01, K08HS026008-01A (AGW)}

\section{References}

1. Maruschak LM, Berzofsky M, Unangst J. Medical problems of state and federal prisoners and jail inmates, 2011-12. Bureau of Justice Statistics. 2015. https://www.bjs. gov/content/pub/pdf/mpsfpji1112.pdf. Accessed $10 \mathrm{Feb}$ 2021

2. Okano JT, Blower S. Preventing major outbreaks of COVID-19 in jails. Lancet. 2020;395(10236):1542-3.

3. Franco-Paredes C, Jankousky K, Schultz J, Bernfeld J, Cullen K, Quan NG, et al. COVID-19 in jails and prisons: a neglected infection in a marginalized population. PLoS Negl Trop Dis. 2020;14(6):e0008409.

4. Becker D. Mass. Prisoners among the first set to get COVID19 vaccine. WBUR. Accessed online 22 Feb 2021: https://www.wbur.org/news/2020/12/13/mass-prisonersamong-the-first-to-get-covid-vaccines

5. Tyson A, Johnson C, Funk C. U.S. public now divided over whether to get COVID-19 vaccine: concerns about the safety and effectiveness of possible vaccine, pace of approval process. Pew Research Center, Science \& Society. https://www.pewresearch.org/science/2020/09/17/u-spublic-now-divided-over-whether-to-get-covid-19-vaccine/ Accessed 8 Jan 2021.

6. Fisher KA, Bloomstone SJ, Walder J, Crawford S, Fouayzi H, Mazor KM. Attitudes toward a potential SARS-CoV-2 vaccine: a survey of U.S. Adults. Ann Intern Med. 2020;173(12):964-73. https://doi.org/10.7326/M20-3569.

7. Bunch L. A tale of two crises: addressing Covid-19 vaccine hesitancy as promoting racial justice. HEC Forum. 2021;33: 143-54. https://doi.org/10.1007/s10730-021-09440-0.

8. Stern MF, Piasecki AM, Strick LB, et al. Willingness to receive a COVID-19 vaccination among incarcerated or detained persons in correctional and detention facilities Four States, September-December 2020. MMWR Morb Mortal Wkly Rep. 2021;70:473-7. https://doi.org/10.15585 /mmwr.mm7013a3.

9. Momplaisir F, Haynes N, Nkwihoreze H, Nelson M, Werner RM, Jemmott J. Understanding drivers of COVID-19 vaccine hesitancy among Blacks. Clin Infect Dis. 2021:ciab102. https://doi.org/10.1093/cid/ciab102.

10. Alsan M, Wanamaker M, Hardeman RR. The Tuskegee Study of Untreated Syphilis: a case study in peripheral trauma with implications for health professionals. J Gen Intern Med. 2020 Jan;35(1):322-5. https://doi.org/10.1007 /s11606-019-05309-8.

11. Nowotny KM, Rogers RG, Boardman JD. Racial disparities in health conditions among prisoners compared with the general population. SSM Popul Health. 2017 Dec;3:48796. https://doi.org/10.1016/j.ssmph.2017.05.011.

12. Price-Haygood EG, Burton J, Fort D, Seoane L. Hospitalization and mortality among Black patients and White patients with Covid-19. N Engl J Med. 2020;382: 2534-43. https://doi.org/10.1056/nejmsa2011686.

13. Stokes EK, Zambrano LD, Anderson KN, et al. Coronavirus disease 2019 case surveillance — United States, January 22May 30, 2020. MMWR Morb Mortal Wkly Rep. 2020;69: 759-65. https://doi.org/10.15585/mmwr.mm6924e2.

14. Jiménez MC, Cowger TL, Simon LE, Behn M, Cassarino N, Bassett MT. Epidemiology of COVID-19 among incarcerated individuals and staff in Massachusetts jails and prisons. JAMA Netw Open. 2020;3(8):e2018851. https://doi. org/10.1001/jamanetworkopen.2020.18851.

15. Lucia VC, Kelekar A, Afonso NM. COVID-19 vaccine hesitancy among medical students. J Public Health (Oxf). 2020:fdaa230. https://doi.org/10.1093/pubmed/fdaa230. 
16. Kwok KO, Li KK, Wei WI, Tang A, Wong SYS, Lee SS. Editor's Choice: Influenza vaccine uptake, COVID-19 vaccination intention and vaccine hesitancy among nurses: A survey. Int J Nurs Stud. 2021;114:103854. https://doi. org/10.1016/j.ijnurstu.2020.103854.

17. CDC. Building confidence in COVID-19 vaccines among your patients: tips for the healthcare team. Accessed online $20 \mathrm{Feb} 2021$ from https://www.cdc.gov/vaccines/covid-19 / d o w n 1 oads / V a c c in a t e W C on fiden c e TipsForHCTeams_508.pdf

18. Kestenbaum LA, Feemster KA. Identifying and addressing vaccine hesitancy. Pediatr Ann. 2015 Apr;44(4):e71-5. https://doi.org/10.3928/00904481-20150410-07.
19. Lewis N, Sisak M. "Hell No": Correctional officers are declining the coronavirus vaccine en masse. The Marshall Project. Accessed online 5 Apr 2021 from https://www. themarshallproject.org/2021/03/15/hell-no-correctionalofficers-are-declining-the-coronavirus-vaccine-en-masse

Publisher's Note Springer Nature remains neutral with regard to jurisdictional claims in published maps and institutional affiliations. 